\title{
To Design \& Develop Mobile - Based Birth Registration System for New Born Baby in Bangladesh
}

\section{Authors: Sabbir Alom Shuvo; Mantasha Altab Noyela; Dr. Md. Fokhray Hossain}

\author{
Affiliation: Daffodil International University; Daffodil International University; Daffodil \\ International University
}

E-mail: shovon961@gmail.com; mantashanoyela4@gmail.com;

\section{drfokhray@daffodilvarsity.edu.bd}

DOI: 10.26821/IJSHRE.9.6.2021.9608

\begin{abstract}
Being a developing country, Bangladesh has digitalized in many sectors but registration process for a new born baby in this country is still the conventional system. Manual method is complex \& can cause inaccurate registration which may lead
\end{abstract} to different problems like invalid identity, cost of registration, loss of birth certificate, wrong population statistics, forgery in information and also it fritters away considerable time. Ensuring every child's birth is must for every country to gather accurate population statistics as it is essential in social and budget planning by a government to allocate enough resources to meet the needs of citizens. So, there is a huge potential of globally accessible mobile-based registration system. The ultimate purpose of this research is to create an automated birth registration system to issue birth certificate immediately to a new born baby in Bangladesh. The proposed system will help the government in terms of being a globally accessible portable system, reducing the cost of registration and by creating a national database for future use. This study aims to establish mass registration including underprivileged people from Sabbir Alom Shuvo; Mantasha Altab Noyela; Dr. Md. Fokhray Hossain, Volume 9 Issue 6, pp 35-46, rural area through mobile system. Registered children will be able get medical support, educational \& all other government facilities through this system. The meaning of a successful registration system is that it should be complete, continuous, permanent and compulsory.

Keywords: Birth registration, Automated system, National Database for new born baby, Civil right

\section{INTRODUCTION}

Birth registration method records a child's birth to the civil register by the govt. authority. For an overpopulated \& developing country like us manual child-birth registration is quite complex and ineffective. Inaccurate birth registration records can cause problems like cost of registering a child, losing registration certificate by the parent and kid, inaccurate population statistics. As correct population statistics is important in social services planning for making certain enough resources to fulfill the requirements of the nation by the government. Birth registration is the key to having civil rights ensuring a child's right to identity [2]. If 
a birth of new born baby goes unregistered then the baby might face difficulties having the civil rights like health card, national identity card and other social services. Child-birth registration became a difficulty of utmost importance as a result of we tend to face difficulties in getting correct population statistics. The current population of Bangladesh is $165,141,838$ on 08 October,2020, [5] based upon latest worldometers info. Currently we are still relying on other data for the population statistics [4]. So, a stable mobile-based automated system for birth registration seems potential in this field. The projected system is going to be ready to assist governing body in terms of getting a conveyable and globally accessible system, rushing up childbirth registration method, reducing price of registering a toddler and capable of keeping registration data.

The current System for Birth registration is manual \& Quite Complex process. Means there is no automation system for registering a Child Birth. In that case, there is no proper national database system for newly born babies in Bangladesh [1]. As a result, it is very difficult for the parents to collect birth certificates while they are enrolling their kids in the school. This project will ensure the establishment of a birth registration system in the underprivileged population of Bangladesh. Also, in manual way it's a long-term process and not secured. People of any age and anywhere can register even if they are not Bangladeshi by forgery. So, we have decided to make a child birth registration system where only a new born baby can be registered and the parents have to confirm their NID so that the process remains secure and valid. This system will be accessible in rural areas and parents will be able to register their child by staying at home with valid information. This will be a stable automated system and also a more effectual, efficient and globally attainable platform for a new birth registration.

As there is no fully functional online birth registration automated system, the aim of this research is to build an efficient \& effective automated system which will issue a birth registration certificate within a short time to new born baby and may keep this record in a database for future use. It will create a proper national database also the system would be accessible from all remote areas of the country. Using this system parents can register child birth without any effort and free of any cost. Don't need to go anywhere just to register their new born baby. This system will reduce their hazards. It will take less time \& will be an effective way of registration. Furthermore, the planned system may additionally be ready to count the particular population of the state with the introduction of proper death registration system.

\section{LITERATURE REVIEW}

On the last decade a number of studies have been published on the importance of birth registration.

Matthew Ellis (2010) states that around 50 million children go unregistered after birth, thus they have no national identity of their own. According to World Bank birth certificate of a child is the medium to get permanent, legal and visible recognition by a state $[9,11]$. If a birth goes unregistered then it will bring barrier to multiple essential services. It wouldn't be possible to receive the adequate resource to maintain successful civil services if birth registration is recognized as basic human right [12]. Again, in most of the developing countries citizens are unaware about the advantages of birth registration.

In 2014, Claudia Cappa, Kendra Gregson, Tessa Wardlaw, Susan Bissell published a paper on Birth 
registration where they mentioned about a child's right and protection. Immediate registration of a child after birth is one of the fundamental human rights. If a state doesn't consider this formal recognition, a child might be unable to get birth certificate which would lead to difficulties obtaining educational and health care services. Birth registration of child is the first step to secure their recognition by the law ensuring their proper rights [14]. Statistics show that only $65 \%$ Children who are younger than 5years are registered worldwide.

UNICEF (2021) affirms that 1 among 4 children under the age of five officially do not exist [15]. Most of the children who are unregistered live in countries where fully functional civil registration system is absent. This research depicts the position of our Country from the table below. In Bangladesh almost $61 \%$ to $80 \%$ of children under age 5 are registered and the rest of them goes unregistered.

Table 1. Percentage of children under age 5 whose births are registered

\begin{tabular}{|c|c|}
\hline STATUS & NAME OF COUNTRIES \\
\hline No data & $\begin{array}{l}\text { Anguilla, Antigua and Barbuda, Bahamas, British Virgin Islands, Brunei Darussalam, } \\
\text { China, Dominica, Eritrea, Fiji, Grenada, Holy See, Kuwait, Libya, Malaysia, Mauritius, } \\
\text { Micronesia, Niue, Palau, Republic of Korea, Saint Kitts and Nevis, Saint Vincent and the } \\
\text { Grenadines, Saudi Arabia, Seychelles, Tokelau, Turks and Caicos Islands }\end{array}$ \\
\hline $\begin{array}{l}1 \% \text { to } 20 \% \text { of } \\
\text { children registered }\end{array}$ & apua New Guinea, Somalia, Zambia \\
\hline $\begin{array}{l}21 \% \text { to } 40 \% \text { of } \\
\text { children registered }\end{array}$ & $\begin{array}{l}\text { Angola, Democratic Republic of the Congo, Guinea-Bissau, Liberia, South Sudan, } \\
\text { Uganda, United Republic of Tanzania, Yemen }\end{array}$ \\
\hline $\begin{array}{l}41 \% \text { to } 60 \% \text { of } \\
\text { children registered }\end{array}$ & $\begin{array}{l}\text { Afghanistan, Bangladesh, Equatorial Guinea, Eswatini, Gambia, Lesotho, Mozambique, } \\
\text { Nepal, Nigeria, Pakistan, Rwanda, Samoa, Timor-Leste, Tuvalu, Vanuatu, Zimbabwe }\end{array}$ \\
\hline $\begin{array}{l}61 \% \text { to } 80 \% \text { of } \\
\text { children registered }\end{array}$ & $\begin{array}{c}\text { Burkina Faso, Cambodia, Cameroon, Central African Republic, Côte d'Ivoire, Ghana, } \\
\text { Guinea, India, Indonesia, Kenya, Lao People's Democratic Republic, Madagascar, } \\
\text { Mauritania, Namibia, Niger, Paraguay, Senegal, Sudan }\end{array}$ \\
\hline $\begin{array}{l}81 \% \text { to } 100 \% \text { of } \\
\text { children registered }\end{array}$ & $\begin{array}{l}\text { Albania, Algeria, Argentina, Armenia, Australia, Austria, Azerbaijan, Bahrain, Barbados, } \\
\text { Belarus, Belgium, Belize, Benin, Bhutan, Bosnia and Herzegovina, Botswana, Brazil, } \\
\text { Bulgaria, Burundi, Cabo Verde, Canada, Chile, Colombia, Comoros, Congo, Cook } \\
\text { Islands, Costa Rica, Croatia, Cuba, Cyprus, Czechia, Democratic People's Republic of } \\
\text { Korea, Denmark, Dominican Republic, Egypt, Estonia, Finland, France, Gabon, Georgia, } \\
\text { Germany, Greece, Guatemala, Guyana, Haiti, Honduras, Hungary, Iceland, Iran, Iraq, } \\
\text { Ireland, Israel, Italy, Luxembourg, Maldives, , San Marino, Sao Tome and Principe, } \\
\text { Serbia, Sierra Leone, Singapore, South Africa, Spain, Sri Lanka, Sweden, Switzerland, } \\
\text { Thailand, Tunisia, Turkey, Turkmenistan, Ukraine, United Arab Emirates, United } \\
\text { Kingdom, United States, Uruguay, Uzbekistan, Venezuela, Viet Nam }\end{array}$ \\
\hline
\end{tabular}




\section{STATEMENT OF PURPOSE}

Registering a new born child birth has become an issue of utmost importance. There is no proper \& well-established birth registration system in Bangladesh to issue the birth certificate to newly born baby which leads to difficulties in acquiring national facilities as a citizen. A birth certificate is an evidence of legal identity, citizenship and serves as a gateway to the acknowledgment of other rights for children [8]. So as a proof of registration a certificate is a must for a child.

Precise population statistics is a must for any government to estimate proper budget plans and social plans ensuring the basic needs of every citizen \& again, if the birth registration process remains incomplete and inaccurate it wouldn't be possible to gain accurate statistics \& it's going to not allot comfortable resources to protection programs, education budgets, or programs designed to combat exploitation. Furthermore, the birth certificate is very important for the citizens of a nation to collect their Health Card, National ID card etc. I

The Bangladesh government has only one Birth Registration System website which is authorized by the government of Bangladesh but that system is not well known nor properly implemented countrywide. A large number of common people goes to the Upazila Centre to register their newborn baby. It is an offline service and also a lengthy process. However, most of the parents are not aware of birth registration [3]. People from rural area aren't concerned about registering a baby immediately after being born.

\section{RESEARCH METHODOLOGY}

Methodology for this research "To Design \& Develop Mobile - Based Birth Registration System for New Born Baby in Bangladesh "is based upon some major functions. Firstly, Applicants information's are required to be collected from the user also valid information of the applicant's parents are required to

submit form. Parent's information can be validated by providing NID number. By providing all information, a submission form will be created to be processed. After successful submission an Application ID will be generated which would be unique. This Application will be used for checking application status and more. All data will be acquired through secured process and information will be saved in server-side database. Initially for the web-based project MySQL will be used for database management. Backend development will be done using Laravel Framework and Bootstrap, react would be used in the Front-end. Again, for data encryption this research project would include the cryptographic hash function. This will ensure a stage of security from data stealing. After verification a unique birth registration number will be generated for the birth certificate which will ensure digital identity of a person. This process will diminish not only the chance of human made errors also going to minimize the possibilities of adulteration in birth certificates.

\section{PROPOSED SYSTEM}

\subsection{System Models}

\subsubsection{System Conceptual Model}

The contextual model also can be said system conceptual model is a framework that illustrates the initial structure of a system with combination of multiple concepts including their behavior and set of actions. This model is required to represent the whole system, basically used to help people understand, know or simulate a particular subject 
that the model depicts. System conceptual model of our proposed system describes the complete environment of project which consists of the respective modules. One of them is the
User/Guardian module another one is the Government Official/admin module. Both of these modules are connected with the central database.

\section{System Conceptual Model}

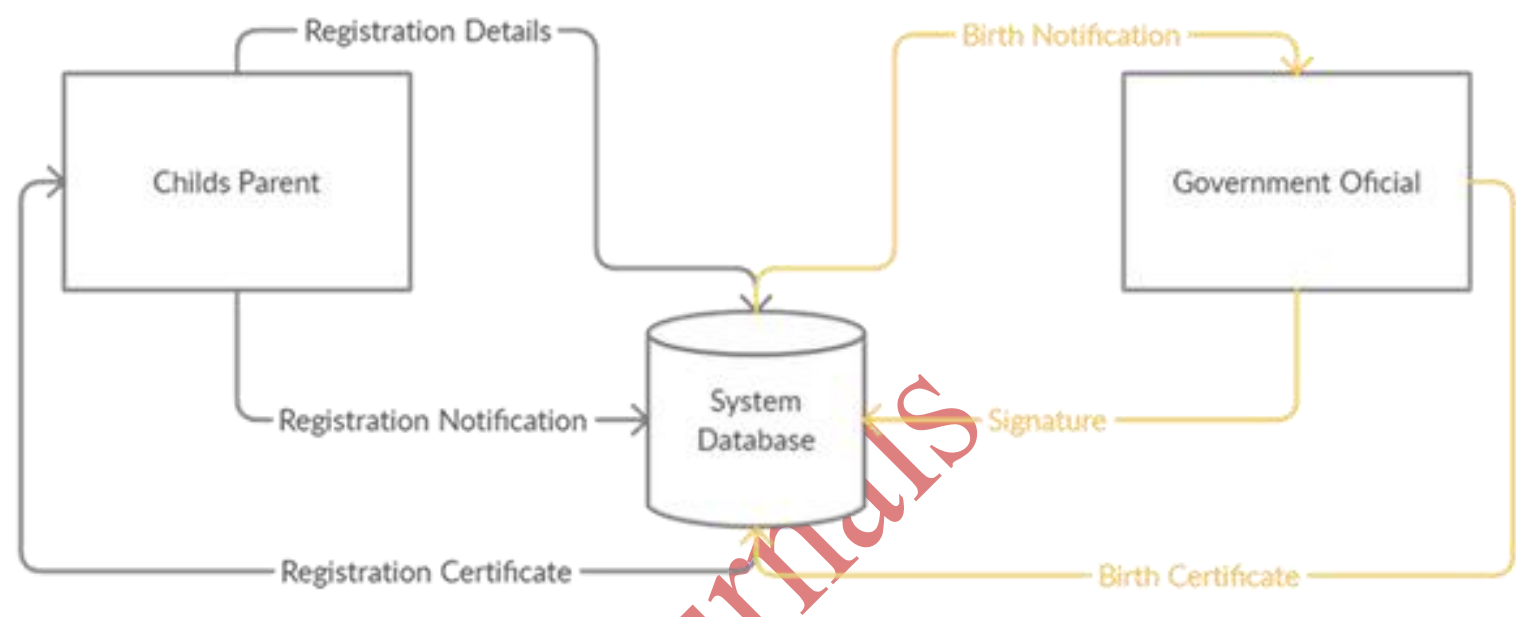

Figure 1: Contextual Model / Concept Model

\subsubsection{Use Case Model of proposed system}

\subsubsection{User System}

The Proposed system has a client side or user side.

Use Case model for User is given below

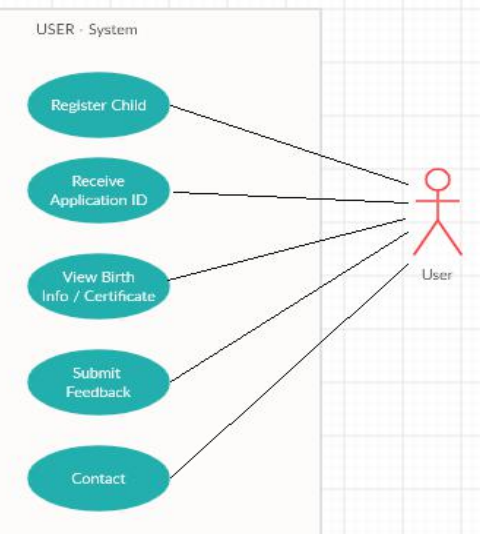

Figure 2: User - System
User opens the web application then navigates to the Registration Section. After submitting required information User gets an Application ID. The ID user can see the application status \& if it's approved then Can Verify Information Form View section. Also, can print the online Certificate from there. Users also can Submit Feedback or report problems. For any kind of help can contact the service providers.

\subsubsection{Admin System}

Admin has to login into the system first. Then he can Check the Applicants. After verifying the information, he can approve the application. Admin can Check the complaints or reports. Then he can attend the feedbacks 


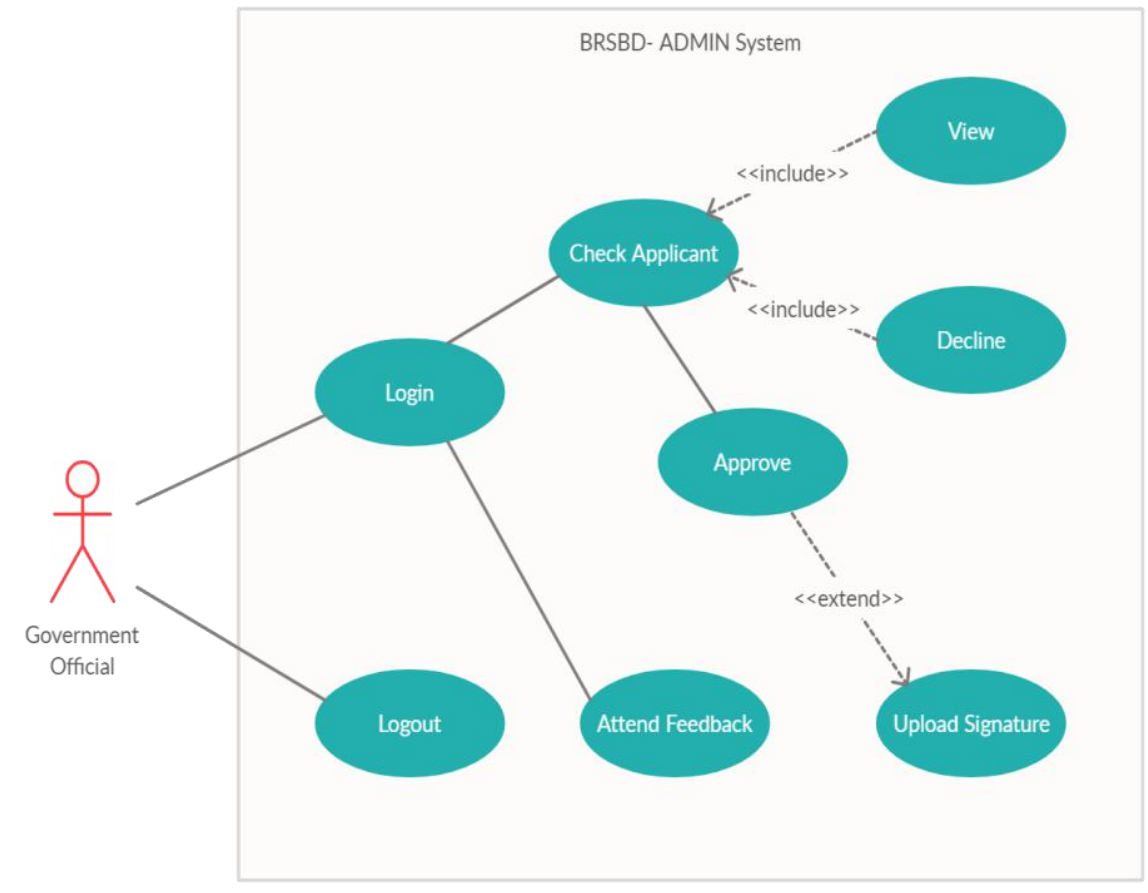

Figure 3 : Admin System

\subsubsection{System Integration}

By integrating both systems the outcome is the unique Birth Registration Number. When User applies for a certificate, it notifies the admin \& then when the admin approves the user gets the Registration number.

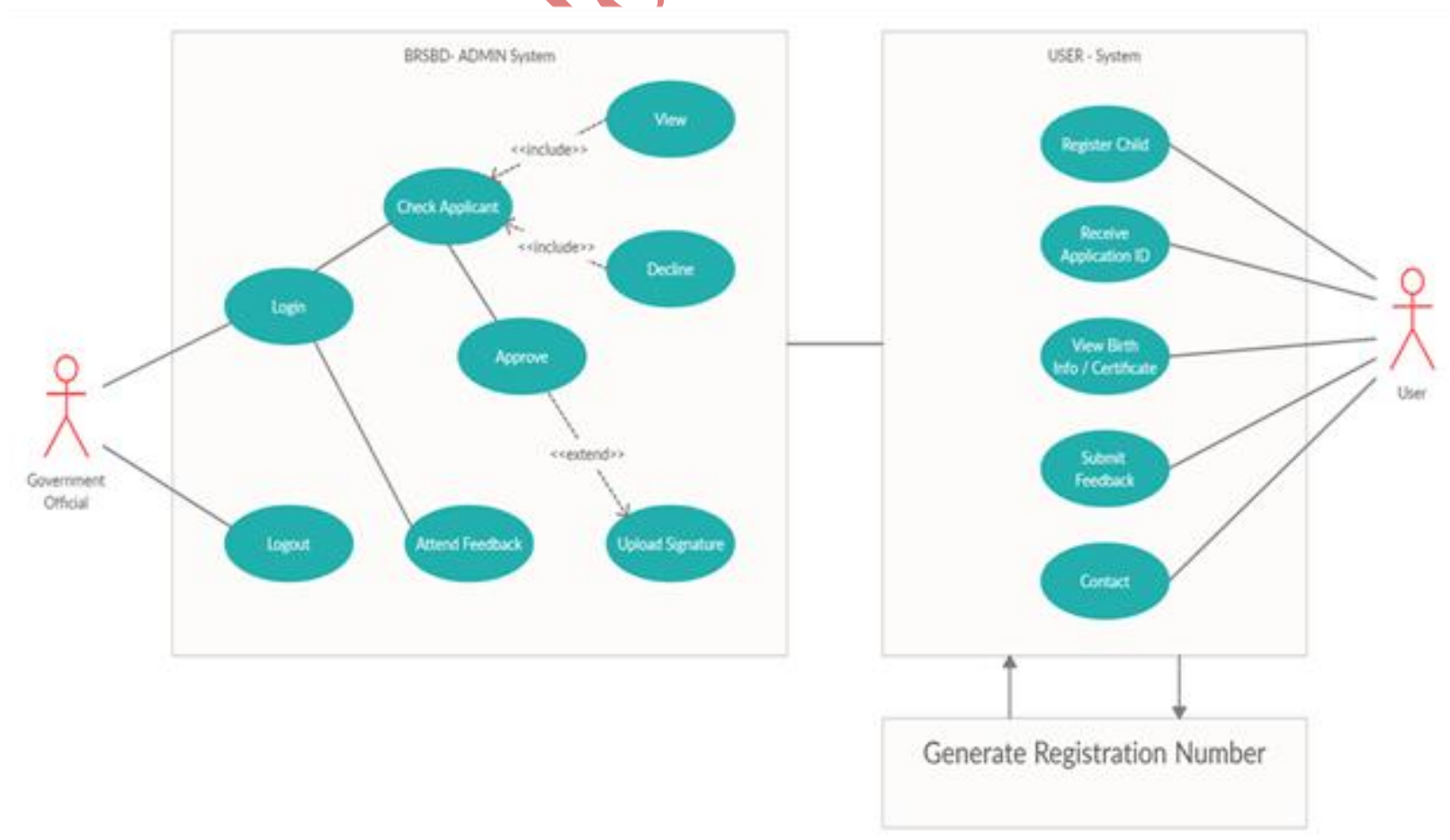

Figure 4: System Integration 


\subsection{The System Flow}

How the whole system works can be understood through the system flow diagram. This diagram depicts data, processes and functions involved in the proposed system.

\subsubsection{System Flow Diagram}

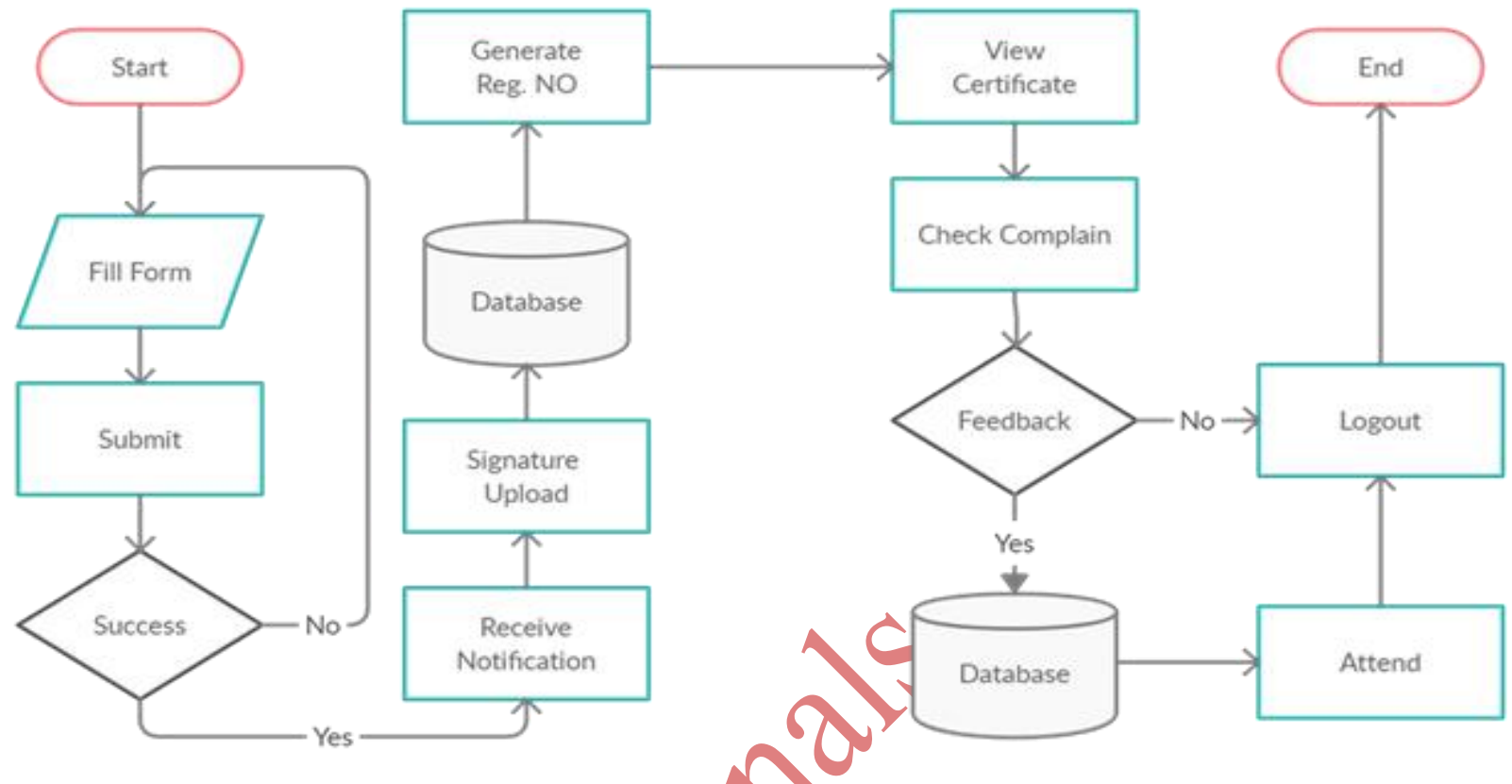

Figure 5: Flow Diagram of Overall System

ER Diagram \& Class Diagram

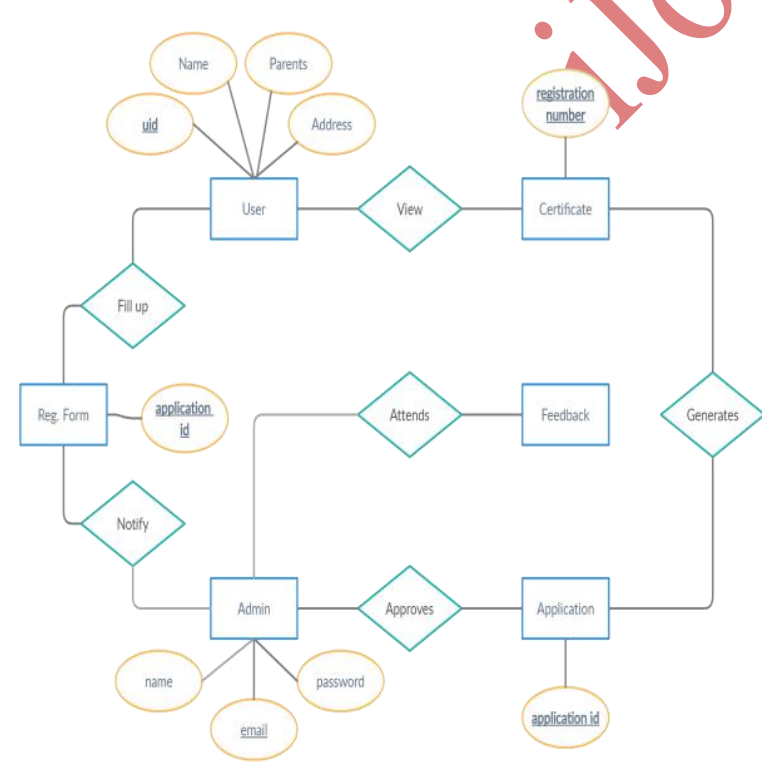

Figure 6: ER Diagram

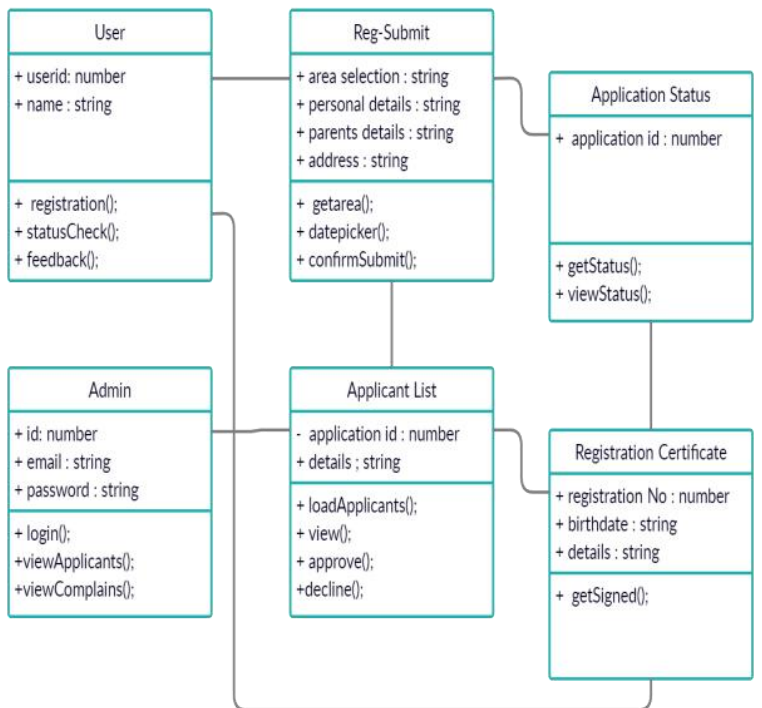

Figure 7: Class Diagram 


\subsection{System Design}

Systems Design can be defined as process of arranging a totally new system or replacing the current system by specifying its parts or modules to assure the desired requirements [10].
In other term, Systems Design focuses on achieving the main objective of the developing system.

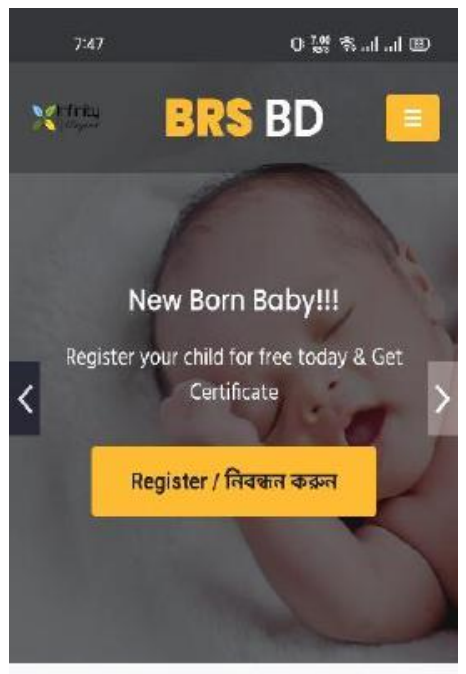

Online Birth

Registration System

Bangladesh

Register now \& Get an Online Certificate
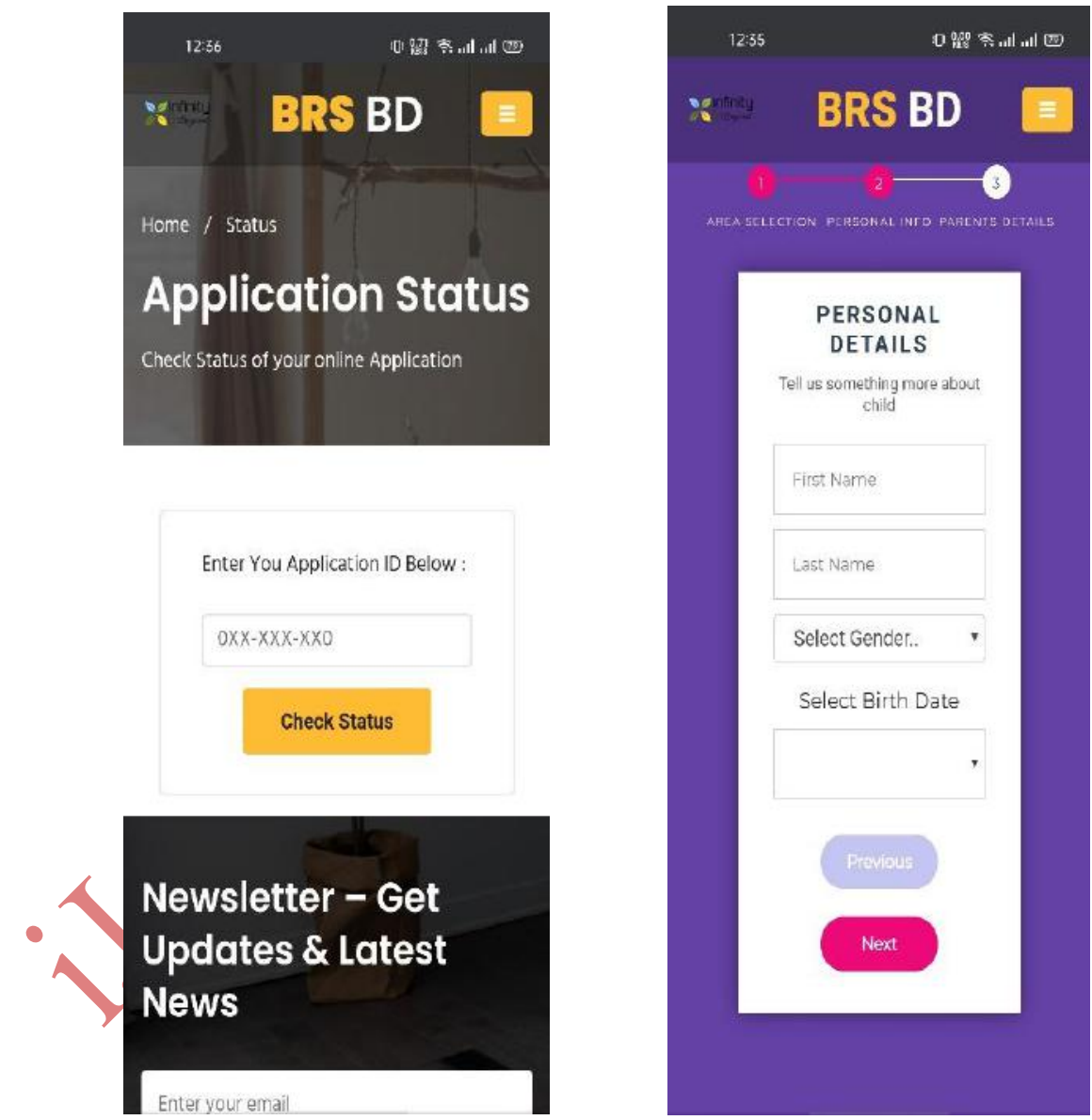

Figure 8: User Interface of Home, Application Status, Registration

\subsection{System Implementation}

In this part, after successful registration one can verify a child's birth information and can download the soft copy of online certificate from this system. If a person enters the full name, fathers NID with accurate birth date then he can view the certificate. Mentioned that, there can be only one person with a full name with fathers NID and birth date, so it gives uniqueness also security as not everyone knows fathers NID. As a result, it would be safe in initial stage for information privacy. 
Volume 9 Issue 6 June 2021

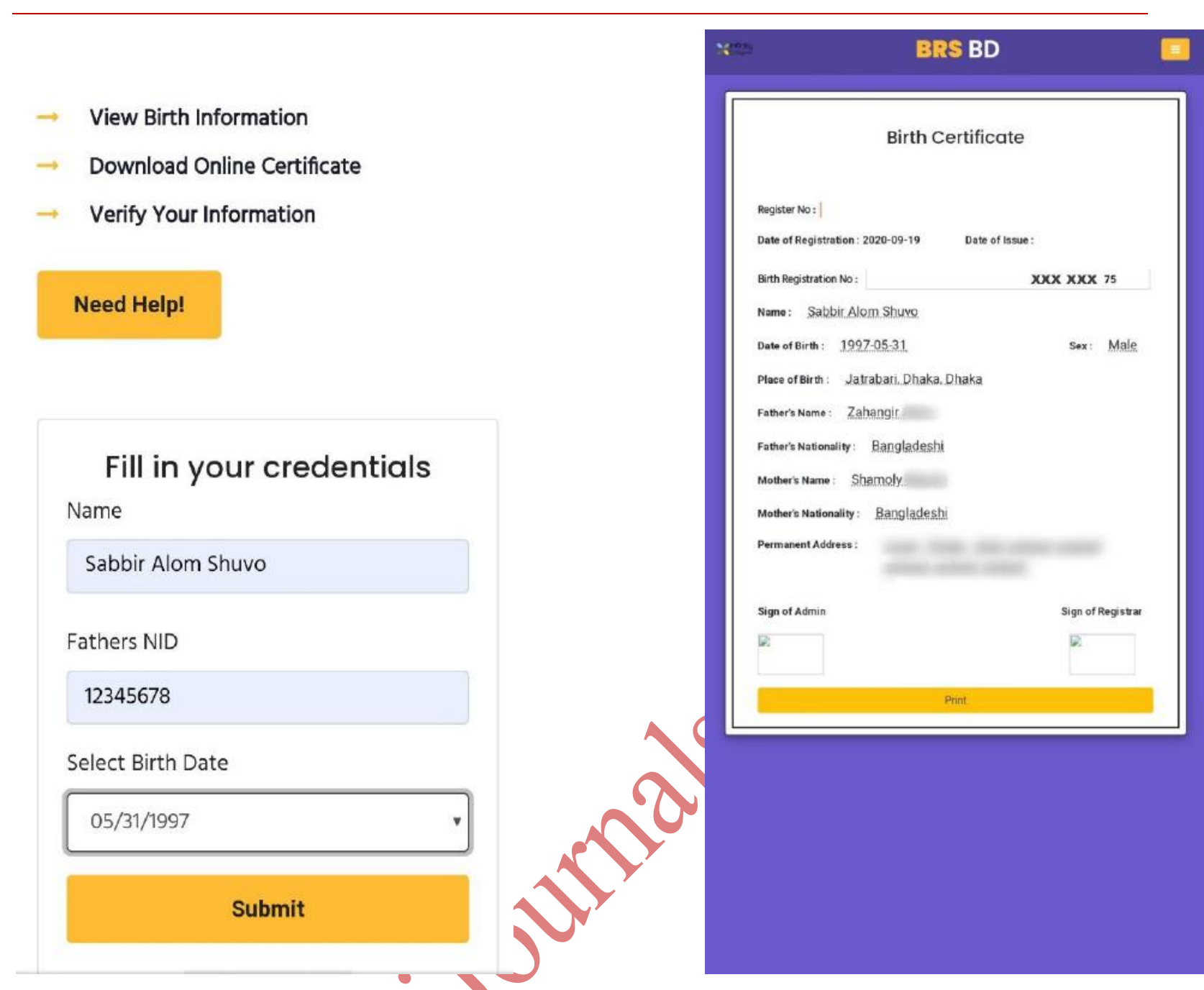

Figure 9: Input, Output from the system

\section{RESULTS \& DISCUSSION}

Initially, we have done the unit testing for the system. Unit test is a type of software testing used by developers with the intention to check and verify each individual module of a system and its outcome. Unit Test Results were satisfactory.

Table 2. Unit Test Result

\begin{tabular}{|c|c|c|c|c|c|c|c|}
\hline $\begin{array}{c}\text { SL } \\
\text { NO }\end{array}$ & Action & Input & $\begin{array}{c}\text { Expected } \\
\text { Output }\end{array}$ & $\begin{array}{c}\text { Actual } \\
\text { Output }\end{array}$ & $\begin{array}{c}\text { Test } \\
\text { Browser }\end{array}$ & $\begin{array}{c}\text { Test } \\
\text { Result }\end{array}$ & Comment \\
\hline 1 & $\begin{array}{c}\text { Area } \\
\text { Selection }\end{array}$ & Dhaka, & Dhaka, & Dhaka, & Chrome & Pass & \\
\hline 2 & $\begin{array}{c}\text { Jatrabari } \\
\text { Jatrabari }\end{array}$ & Jatrabari & Pending & Pending & Chrome & Pass & \\
\hline 3 & $\begin{array}{c}\text { Birth Info } \\
\text { Check }\end{array}$ & Abdul Hamid & $\begin{array}{c}\text { Not } \\
\text { Approved }\end{array}$ & $\begin{array}{c}\text { Not } \\
\text { Approved }\end{array}$ & Chrome & Pass & \\
\hline
\end{tabular}




\subsection{Discussion}

At a glance we can say that, proposed system is an automated mobile \& browser friendly system which ensures smooth \& fast experience with security. The proposed system will provide A national secure Database system. In Short, it would be an Efficient and effective system. But to implement it has some major challenges too. It would be totally dependent on server and whole country-based coverage needed. To implement successfully, geographically an office is needed in each unit area. The proposed system also will create some other opportunities for the citizens. After implementation there will a huge scope of employment for maintenance. People from rural areas will get the chance to have facilities by government. We have encountered some potential risks too. There might be a lot of foreign companies who can help us to build in the birth registration system. As it is a matter of our security, it can be a threat for our country. We should make sure there is no interference of Foreign Companies. Also set of rules and regulations with policies must be imposed by the government. Unsuccessful implementation of rules and regulations can bring problems.

\section{CONCLUSION}

Child Birth Registration System is a process of registering the newborn from home/hospital through online. The ultimate purpose of our proposal research is to take the existing system from manual to automated system. Each developed country has digital system for the birth registration [6]. So, we should look forward for this digital system as we live in modern era where everything is online and people prefer digital way of doing things where effort will be less and would be less time consuming [7]. As our current system is manual, it is quite complex and ineffective. Also, the only verified online system is not properly functional and doesn't generate an online birth certificate as a result getting a certificate is time consuming lengthy process. Proposed system will make birth registration process automated and online including the ability to issue a certificate to a new born baby within a short range of time.

The proposed system has been developed for both the citizen of Bangladesh \& government of Bangladesh. People can access it from the rural area \& can register for the new born baby free of any cost. Reduction of cost will bring interest of the poor parent complete the registration. They will get the certificate without facing any hazard. This certificate will ensure the basic needs of baby, like primary education, health care, health insurance and also other government facilities of the citizen of the nation.

In this research, the System Conceptual model and few other models have been introduced to understand the basic structure \& function of the proposed system. In the functioning part, the system consists of various modules including a registration form, authentication and verification panel \& a certificate generator. The guardian uses the user UI and for the government official to provide certificate there is admin module.

The research outcome can be successfully gained by implementing policies in accordance with the rules and regulations of Bangladesh by the Government. In spite of the fact that technology only can offer systems to be more effective and feasible, the basic groundwork needs to be laid in terms of raising demand and improving accessibility to families [13]. When birth 
registration will be mandatory for all, there will be a national database of the under-age people. Then the Government can make accurate plans for the children \& distribute different facilities throughout the registration. Also, there will be a huge number of employment scope while implementing this system in different areas in Bangladesh to establish the automated birth registration.

By providing all children with proof of legal identity from day one, their rights can be protected and universal access to social services can be enabled [13]. As a nation, if all comes forward to fulfil their promise to leave no one behind, the government must ensure that every child is registered at birth and receives a passport to lifelong protection $-\mathrm{a}$ birth certificate.

\subsection{Future Work}

The System is not only for measuring the number of new born babies but also this will also integrate numbers of day 1 to 18 years adult. As this numbers are out of voter IDs. When we include this number with the Voters number and reducing the death number, we can get the actual number of the population utilizing automation system. So, we can say that this system needs 18 years to be matured \& we need to introduce another system to this which is the death registration system. The actual population statistics is important for each and every country or nation. Currently we are depending on others data \& each organization gives different data which is inefficient. By implementing this system, we can get a functional system with a proper national database \& actual Population Statistics utilizing automation system.

\section{ACKNOWLEDGMENTS}

We would like to express our deep appreciation and indebtedness to our supervisor Dr. Md. Fokhray Hossain for endless support, kindness, and understanding during the project duration.

Also, we wish to extend our special thanks to all our family and friends who supported us in one way or another.

Above all, we would like to thank the Great Almighty for always having his blessing on us.

\section{REFERENCES}

[1]. "Birth Registration in Bangladesh", br.lgd.gov.bd, 2020. [Online]. Available:

http://br.lgd.gov.bd/files/Birth\%20Registration \%20in\%20Bangladesh.pdf. [Accessed: 09(Oct-2020].

[2]. "Timely and accessible birth registration", Unicef.org, 2020. [Online]. Available:

https://www.unicef.org/bangladesh/en/timelyand-accessible-birth-registration. [Accessed: 09- Oct- 2020].

[3]. "Digital birth registration in Bangladesh", Plan International, 2020. [Online]. Available: https://plan-

international.org/publications/digital-birthregistration-bangladesh. [Accessed: 09- Oct2020].

[4]. "Bangladesh (BGD) - Demographics, Health \& Infant Mortality - UNICEF DATA", UNICEF DATA, 2020. [Online]. Available: https://data.unicef.org/country/bgd/.

[Accessed: 09- Oct- 2020].

[5]. "Bangladesh Population (2020)

Worldometer", Worldometers.info, 2020.

[Online]. Available: 
https://www.worldometers.info/worldpopulation/bangladesh-population/. [Accessed: 09- Oct- 2020].

[6]. Higgs, "UK birth registration and its present discontents", Reproductive Biomedicine \& Society Online, vol. 5, pp. 35-37, 2018. Available: 10.1016/j.rbms.2017.11.001.

[7]. D. Zalitis, "Pregnancy, birth and babies in the online digital world", Women and Birth, vol. 26, p. S41, 2013. Available: 10.1016/j.wombi.2013.08.220.

[8]. Mbise, "Birth Certificates, Birth Registration and the Denial of Human Rights: Evidence from Tanzania National Panel Data 2010/11", International Journal of Children's Rights, vol. 28, no. 2, pp. 243-257, 2020. Available: 10.1163/15718182-02802002.

[9]. The World Bank. Early Child Development. General Policy \#7-Provide Birth Certificates for Undocumented Young People http://siteresources.worldbank.org/ INTCY/Resources/3957661187899515414/SY AR genpoli7.pdf (4 April 2009, date last accessed).

[10]. K. Kendall and J. Kendall, Systems analysis and design, 10th ed. Rutgers University Julie E Kendall, Rutgers University, 2019.
[11]. Ahmed S, Dincu I. Birth Registration: Challenges and Responses, Plan International Cambodia, 2005 http://ssl.brookes.ac.uk/ubr/files/1/42Cambodi a_Article_UBR_Final.pdf (4 April 2009, date last accessed).

[12]. Dodds, Jennifer \& Ellis, Matthew. (2010). Birth registration is a priority for child survival. Journal of tropical pediatrics. 56. 734. 10.1093/tropej/fmq021.

[13]. Hereward, Mark \& Williams, Cornelius \& Petrowski, Nicole \& Cappa, Claudia. (2019). Universal birth registration by 2030: progress and challenges. Lancet (London, England). 394. 10.1016/S0140-6736(19)33101-0.

[14]. Cappa, C., Gregson, K., Wardlaw, T., \& Bissell, S. (2014). Birth registration: A child's passport to protection. The Lancet Global Health, 2(2). doi:10.1016/s2214109x(13)70180-3.

[15]. UNICEF DATA. 2021. Birth registration UNICEF DATA. [online] Available at: $<$ https://data.unicef.org/topic/childprotection/birthregistration/?fbclid=IwAR1HxWXgzA9BPKC Gu96P3yj0ZIQFCbbHIAnKKbB3eQIGD7U2c TahjPIHeQ> [Accessed 16 February 2021. 